\title{
Deposition of Super Hydrophobic a-C:F Films by Dielectric Barrier Discharge at Atmospheric Pressure
}

\author{
Duk Jae Kimª, Yoon-Kee Kim", Jeon Geon Han ${ }^{\mathrm{c}}$ \\ ${ }^{a}$ Geniatech Inc., GSBC Bldg., Suwon, Korea \\ ${ }^{b}$ Department of Welding and Production Engineering, Hanbat National University, Daejeon 305-764, Korea \\ 'Department of Advanced Materials Science \& Engineering, Sungkyunkwan University, Suwon, Korea
}

(Received March 22, 2011; revised April 25, 2011; accepted April 29, 2011)

\begin{abstract}
Hydrophobic a-C:F film was coated on polycarbonate film with $\mathrm{CF}_{4}, \mathrm{C}_{2} \mathrm{~F}_{6}$ and $\mathrm{HFC}\left(\mathrm{C}_{2} \mathrm{~F}_{4} \mathrm{H}_{2}\right)$ gas in helium discharge generated by $5 \sim 100 \mathrm{kHz}$ AC power supply at atmospheric pressure and room temperature. The highest water contact angle of the a-C:F film formed with $\mathrm{He}_{2} / \mathrm{C}_{2} \mathrm{~F}_{6}$ mixed gas is $155^{\circ}$. X-ray photoelectron spectrum showed that there was $40 \%$ of $\mathrm{C}_{-}-\mathrm{CF}_{3}$ bond at the surface of the super hydrophobic film. The contact angle and deposition rate were decreased with increasing substrate temperature. The contact angle was generally increased with the surface roughness of the film. The contact angle was high when the surface microstructure of the film was fine and sharp at the similar roughness and chemical composition of the surface.
\end{abstract}

Keywords: Hydrophobic coatings, Fluorinated coating, Dielectric barrier discharges (DBD), Atmospheric pressure glow discharges (APGD)

\section{Introduction}

Polymer films deposited by plasma technology have been extensively studied due to their strong potential for the various applications. Since the properties of the films is drastically changed and easily controlled by the plasma conditions such as plasma density, gas composition, frequency of the power source, it is possible to add various useful functions on the polymer surface using plasma technology as followings: protective coatings, gas barriers, hydrophobic coatings, optical coatings, biocompatible films, and moisture sensors. Especially, various transparent polymers with hydrophobic coating will be used in the applications such as eye glasses, cover glasses for solar cells, windshields of automobiles, and so on ${ }^{1)}$.

Hydrophobic property is mainly governed by chemical properties and the geometry of the film surface $^{2-4)}$. Fluorocarbon polymers such as PTFE show stable and strong hydrophobic property due to

\footnotetext{
*Corresponding author. E-mail : ykkim@hanbat.ac.kr
}

low surface energy. In order to produce films having low surface energy, it is necessary to introduce a high concentration of $\mathrm{CF}_{3}$ bonding into the films ${ }^{5}$. The surface topography of the film also plays a great role in the hydrophobic property independently of surface chemical functionality ${ }^{6}$.

There were many reports of methods to make super hydrophobic surface such as template, photolithography, plasma etching, colloidal assemblies, layer-by-layer deposition, sol-gel, membrane casting, electrospinning, et $a l^{7)}$ Unfortunately, most of them were not suited for mass production for large surface. Dielectric barrier discharge (DBD) generated at atmospheric pressure is possible to coat thin film on large area substrate without any vacuum chamber and expensive pumping system. In thin film coating process using plasma, the chemical bonding and topography of film are easily controlled by plasma conditions including plasma density, gas composition, and process temperature et al.

In this paper, we tried to deposit hydrophobic thin layer using several fluorocarbon gas DBD at atmospheric pressure. The effects of the chemical 
bonding state related with fluorine and surface morphology of the films on the hydrophobicity were studied using X-ray photoelectron spectrum and atomic force microscopy (AFM). We discussed the combinations of chemical and morphological factors for super hydrophobic coating.

\section{Experimental}

The DBD system for atmospheric pressure deposition used in this study was consisted of gas supply parts, reaction container and power supply. Helium, $\mathrm{CF}_{4}$, $\mathrm{C}_{2} \mathrm{~F}_{6}$ and HFC $\left(\mathrm{C}_{2} \mathrm{~F}_{4} \mathrm{H}_{2}\right)$ were used to improve the hydrophobicity of Polycarbonate (PC). These gases $(0.5 \mathrm{slm})$ were fed into the rectangular container by a ball flow meter with a constant gas flow rate. Helium (2slm) was introduced for stabilizing glow discharge and preventing abnormal transition of discharge to arc or streamer at atmospheric pressure. The discharges were generated and sustained at $4 \mathrm{kV}$ by $5 \sim 100 \mathrm{kHz}$ AC power supply. All experiments were performed at $30^{\circ} \mathrm{C}$ and $100^{\circ} \mathrm{C}$.

The DBD was generated between two opposite electrodes (upper electrode and lower electrode). The lower electrode was covered with thin alumina $\left(\mathrm{Al}_{2} \mathrm{O}_{3}\right)$ plate of $2.7 \mathrm{~mm}$ thickness and designed to be heated up to $250^{\circ} \mathrm{C}$ by the resistant heater installed inside the electrode. Gap distance between the two electrodes was varied within $4 \mathrm{~mm}$ in case of using PC as a substrate. At atmospheric pressure, stable discharge could be obtained in the frequency range of $5 \sim 100 \mathrm{kHz}$ and the voltage within $15 \mathrm{kV}$. The deposition time for the hydrophobic coating was $10 \mathrm{~min}$.

The hydrophobicity of the coating was evaluated using a contact angle meter (SEO 300A) with water droplet at $30^{\circ} \mathrm{C}$ in air. The size of water droplet was $5 \mathrm{~mm}$. Chemical composition and structures of the films were analyzed by FT-IR (ABB Bomem) and X-ray photoelectron spectroscopy (XPS, MultiLab ESCA 2000). The thickness of films were measured by surface profiler (TENCOR, P-10) and surface morphologies were observed with Atomic Force Microscope (AFM, Thermo Microscope, CP Research Type) with Si tip at constant load of $10 \mathrm{nN}$.

\section{Results and Discussion}

\subsection{Contact angle and surface morphology}

The photographs of water droplet on PC substrates treated by DBD using fluorocarbon gases at room

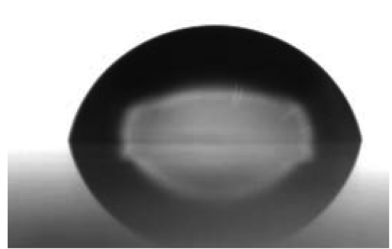

(a)

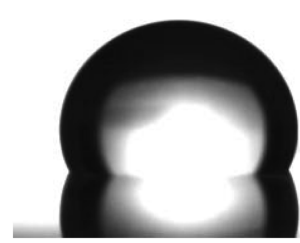

(c)

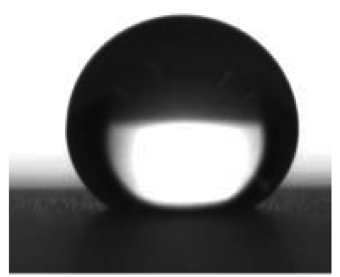

(b)

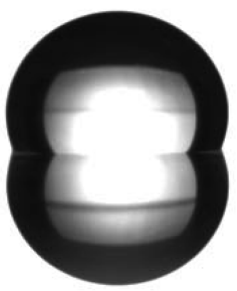

(d)
Fig. 1. Photographs of water drop about $5 \mathrm{~mm}$ in diameter on coated PC with (a) untreated, (b) $\mathrm{He} / \mathrm{C}_{2} \mathrm{~F}_{6}$, (c) $\mathrm{He} / \mathrm{CF}_{4}$, (d) $\mathrm{He} / \mathrm{HFC}$.

Table 1. Surface properties of the films deposited with several fluorocarbon gases

\begin{tabular}{|c|c|c|c|}
\hline & $\begin{array}{c}\text { Contact } \\
\text { angle }\end{array}$ & $\begin{array}{c}\text { Surface } \\
\text { roughness }\end{array}$ & Thickness \\
\hline $\mathrm{He} / \mathrm{CF}_{4}$ & $115^{\circ}$ & - & - \\
\hline $\mathrm{He} / \mathrm{C}_{2} \mathrm{~F}_{6}$ & $155^{\circ}$ & $35 \mathrm{~nm}$ & $0.18 \mu \mathrm{m}$ \\
\hline $\mathrm{He} / \mathrm{HFC}$ & $113^{\circ}$ & $24 \mathrm{~nm}$ & $3.1 \mu \mathrm{m}$ \\
\hline
\end{tabular}

temperature and atmospheric pressure are shown in Fig. 1. The contact angles of the water drops were in the range of $110 \sim 155^{\circ}$ as shown in Table 1 . Especially, the film coated using $\mathrm{He} / \mathrm{C}_{2} \mathrm{~F}_{6}$ mixed gases showed the highest contact angle of $155^{\circ}$ which was more than two times as high as that of untreated PC, $75^{\circ}$. The contact angle was decreased from $155^{\circ}$ to $115^{\circ}$ with increasing substrate temperature from $30^{\circ} \mathrm{C}$ to $100^{\circ} \mathrm{C}$. The deposition rate was also decreased with increasing substrate temperature. The thicknesses of the films coated at $30^{\circ} \mathrm{C}$ and $100^{\circ} \mathrm{C}$ were $0.18 \mu \mathrm{m}$ and $0.13 \mu \mathrm{m}$, respectively.

Fig. 2 shows AFM images of the surface coated with $\mathrm{He} / \mathrm{C}_{2} \mathrm{~F}_{6}$ gases at $30^{\circ} \mathrm{C}$ and $100^{\circ} \mathrm{C}$, respectively. The surface of coated layer was very rough compared with that of untreated $\mathrm{PC}$ as shown in Fig. 2. The topography of the thin layer deposited at $30^{\circ} \mathrm{C}$ was sharper than that of the film deposited at $100^{\circ} \mathrm{C}$. The root-mean-squire(rms) roughness values of coated layer at $30^{\circ} \mathrm{C}$ and $100^{\circ} \mathrm{C}$ were $35 \mathrm{~nm}$ and $46 \mathrm{~nm}$, 


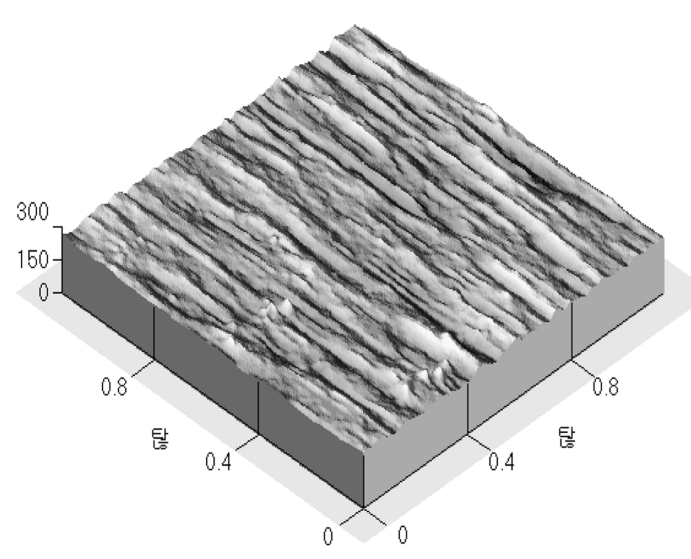

(a)

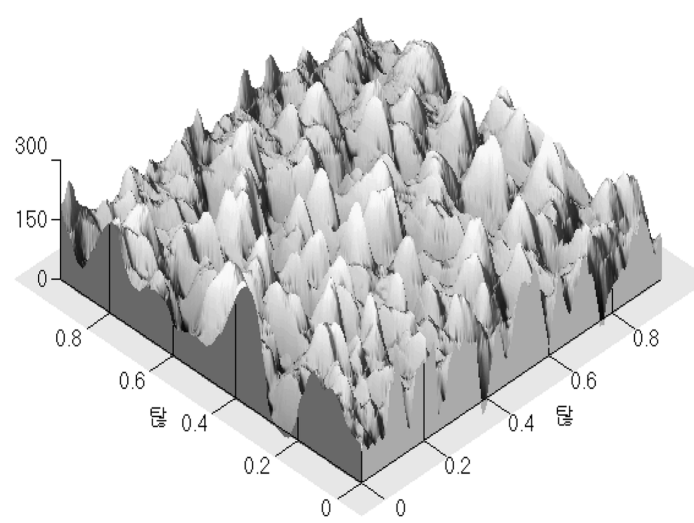

(c)

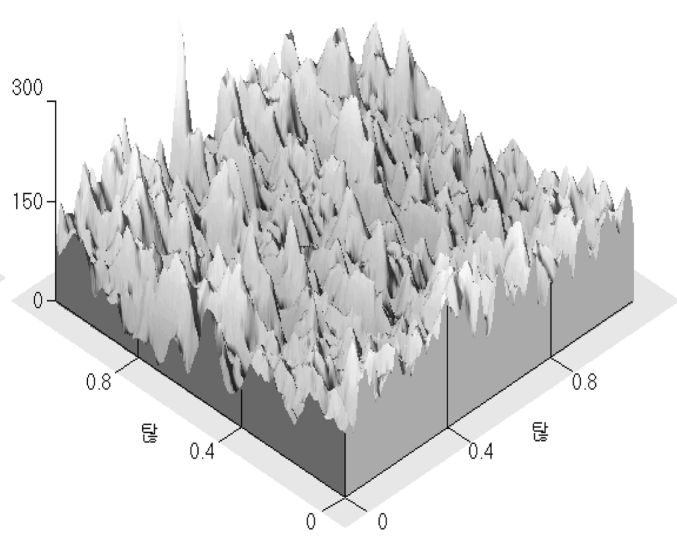

(b)

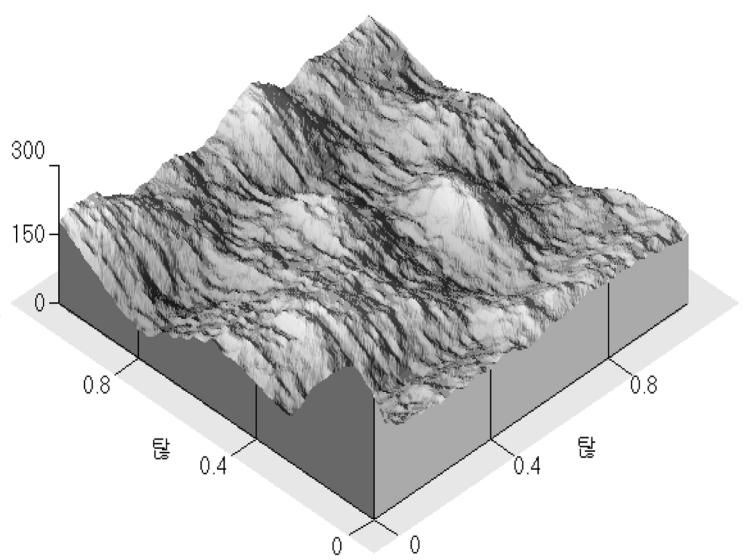

(d)

Fig. 2. AFM surface morphologies of $P C$ (a) as-received, (b) coated with $\mathrm{He} / \mathrm{C}_{2} \mathrm{~F}_{6}$ at $30^{\circ} \mathrm{C}$, (c) coated with $\mathrm{He} / \mathrm{C}_{2} \mathrm{~F}_{6}$ at $100^{\circ} \mathrm{C}$, (d) coated with $\mathrm{He} / \mathrm{HFC}$ at $30^{\circ} \mathrm{C}$.

respectively. Even though the film deposited at $100^{\circ} \mathrm{C}$ had rougher surface, it showed the lower contact angle because that the layer coated at $30^{\circ} \mathrm{C}$ had sharper surface structure. Water droplets on super-hydrophobic surfaces like as lotus leaf, which have hierarchical micrometer- and nanometer-sized structures, readily sit on the apex of the nanostructures because air bubbles fill in the valleys of the structure under the droplet ${ }^{8-10}$. Water drops on this kind of surface cannot penetrate into the micro- or nanostructures and wet the surface, resulting in extremely high contact angles. So we believed that the sharper structure showed higher contact angle of water droplet because it had small apex and deep valleys. Fig. 2(d) shows the AFM image of the films deposited using He/HFC. The topography of the film was like round hill and rms roughness value of it was $24 \mathrm{~nm}$. The contact angle of the film was $113^{\circ}$ which is much low compared with that coated with $\mathrm{He} / \mathrm{C}_{2} \mathrm{~F}_{6}$ at room temperature. The thickness of the film coated with $\mathrm{He} / \mathrm{HFC}$ was $3.1 \mu \mathrm{m}$. In case of using $\mathrm{He} / \mathrm{CF}_{4}$, film was not deposited on the $\mathrm{PC}$ substrate.

\subsection{Composition and chemical bonding states analysis by XPS}

The C1s core-level XPS spectra obtained from the films deposited using fluorocarbon gases were shown in Fig. 3. The spectra for $\mathrm{He} / \mathrm{C}_{2} \mathrm{~F}_{6}$ (Fig. 3(a)), $\mathrm{He} / \mathrm{CF}_{4}$ (Fig. 3(b)) and He/HFC (Fig. 3(c)) were deconvoluted into peaks, and marked in order of decreasing binding energy to $\mathrm{CF}_{3}, \mathrm{CF}_{2}, \mathrm{C}=\mathrm{O}, \mathrm{CF}, \mathrm{CF}_{\mathrm{x}}$ and $\mathrm{C}-\mathrm{C}$. The ratio of bonding according to the reaction gases listed in Table 2. When $\mathrm{C}_{2} \mathrm{~F}_{6}$ was used as a reaction gas, $\mathrm{CF}_{3}$ and $\mathrm{C}-\mathrm{C}$ binding were main binding structure of the film, as shown in Fig. 3(a). Thus, it is believed that $\mathrm{C}_{2} \mathrm{~F}_{6}$ is broken at $\mathrm{C}-\mathrm{C}$ bond and converted into two $\mathrm{CF}_{3}$ during deposition process because the biding energy of $\mathrm{C}-\mathrm{C}$ bond is $3.61 \mathrm{eV}$ and $\mathrm{C}-\mathrm{F}$ is $5.53 \mathrm{eV}^{11)}$. It is well known that hydrophobicity increase with the amount of $\mathrm{CF}_{3}$ bonding $^{5)}$. As shown in Fig. 3(b) and (c), however, 


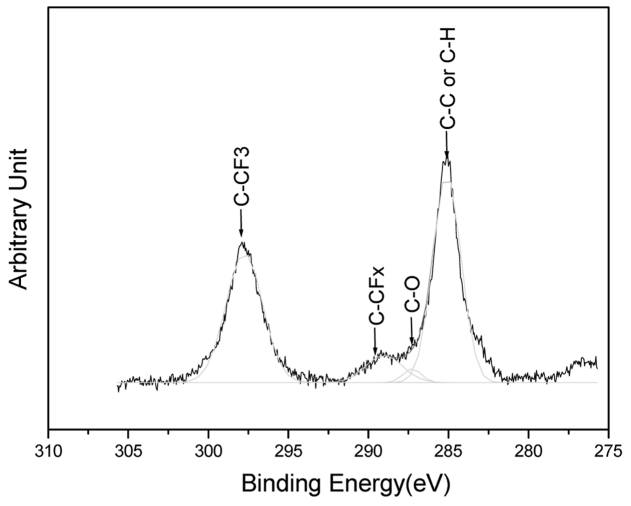

(a)

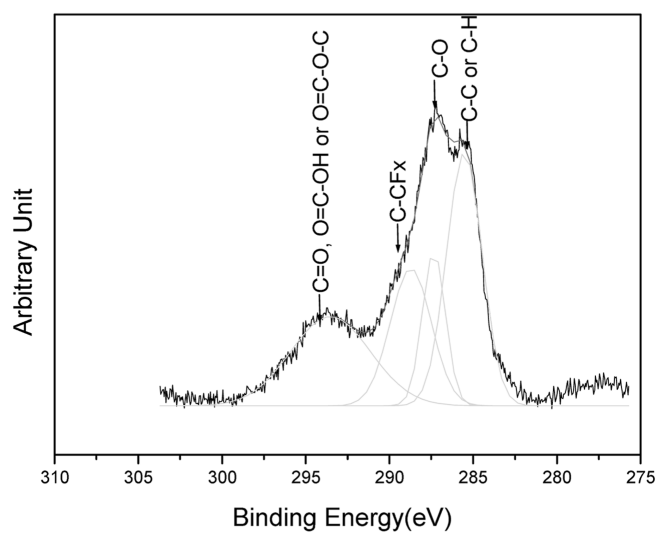

(b)

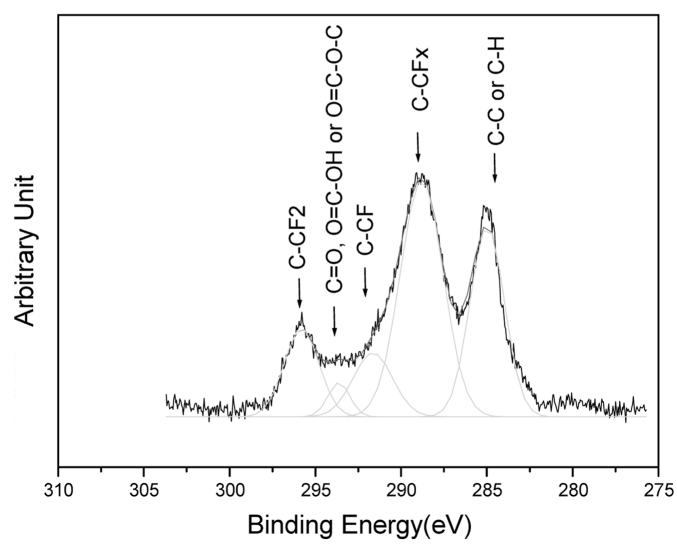

(c)

Fig. 3. C1s core-level XPS spectra of PC (a) coated with $\mathrm{He} / \mathrm{C}_{2} \mathrm{~F}_{6}$ at $30^{\circ} \mathrm{C}$, (b) treated with $\mathrm{He} / \mathrm{CF}_{4}$, (c) coated with $\mathrm{He} / \mathrm{HFC}$.

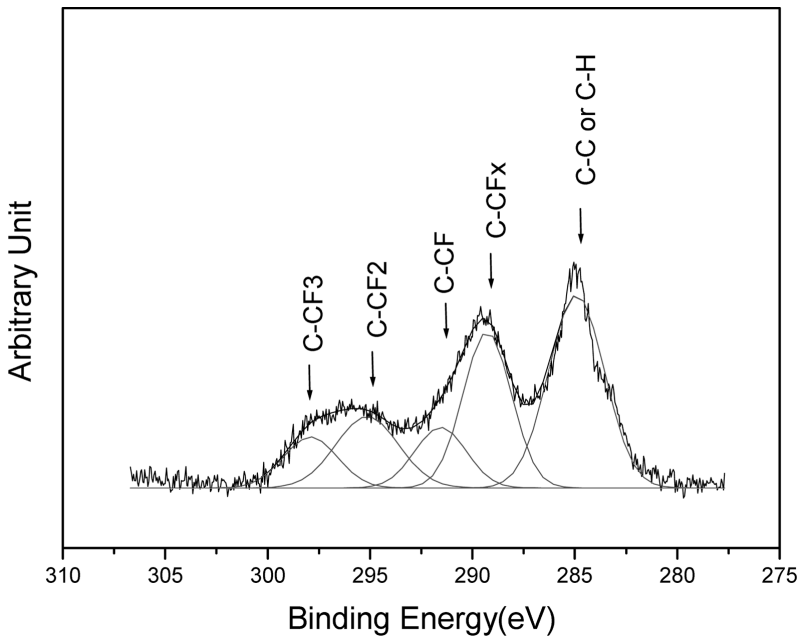

Fig. 4. C1s core-level XPS spectra of PC coated with $\mathrm{He} / \mathrm{C}_{2} \mathrm{~F}_{6}$ at $100^{\circ} \mathrm{C}$.

$\mathrm{C}-\mathrm{O}, \mathrm{CF}_{\mathrm{x}}$ and $\mathrm{C}-\mathrm{C}$ bonding were the main binding structure of the films coated using $\mathrm{He} / \mathrm{CF}_{4}$ and $\mathrm{He} /$ $\mathrm{HFC}$. In case of using $\mathrm{CF}_{4}$ as a reaction gas, $\mathrm{CF}_{\mathrm{x}}$ and $\mathrm{C}-\mathrm{O}$ were observed but $\mathrm{CF}_{3}$ peak was not found. Since deposition was conducted at atmospheric pressure in a container which was not tightly sealed there might be a small amount of oxygen. This can explain the detection of the $\mathrm{C}-\mathrm{O}$ peak without intentionally introducing oxygen gas. When using HFC gas as a fluorine source, $\mathrm{CF}_{2}$ and $\mathrm{CF}_{\mathrm{x}}$ bonding were mainly observed. From the above results, $\mathrm{C}_{2} \mathrm{~F}_{6}$ is one of the best to obtain super hydrophobic film.

Fig. 4 shows the XPS spectrum of the film deposited at $100^{\circ} \mathrm{C}$ using $\mathrm{C}_{2} \mathrm{~F}_{6}$. The $\mathrm{CF}_{3}$ peak was observed in the spectrum. But the intensity of the peak was smaller than that observed from the film deposited at $30^{\circ} \mathrm{C}$ as shown in Fig. 3(a). This implies that some of $\mathrm{CF}_{3}$ decomposed from $\mathrm{C}_{2} \mathrm{~F}_{6}$ were recombined at higher temperature. The relative amounts of $\mathrm{C}, \mathrm{F}$ and $\mathrm{O}$ of the film deposited using different fluorocarbon gas were listed in Table 3. The highest fluorine content was obtained from the film deposited using $\mathrm{C}_{2} \mathrm{~F}_{6}$. The film deposited using $\mathrm{C}_{2} \mathrm{~F}_{6}$ at $100^{\circ} \mathrm{C}$ showed higher oxygen content and lower fluorine than that at $30^{\circ} \mathrm{C}$. This is one of the reason

Table 2. The component ratios of PC substrate and the films coated with several fluorocarbon gases from the results of XPS C1s spectra

\begin{tabular}{|l|c|c|c|c|c|c|c|}
\hline & $\mathrm{CF}_{3}$ & $\mathrm{CF}_{2}$ & $\mathrm{C}_{-} \mathrm{CF}_{\mathrm{x}}$ & $\mathrm{CF}$ & $\mathrm{C}-\mathrm{C}$ & $\mathrm{C}-\mathrm{O}$ & $\mathrm{C}=\mathrm{O}$ \\
\hline $\mathrm{PC}(\mathrm{Subs})$. & - & - & - & - & 84 & 8 & 8 \\
\hline $\mathrm{He} / \mathrm{C}_{2} \mathrm{~F}_{6}$ & 40 & - & - & - & 50 & 10 & - \\
\hline $\mathrm{He} / \mathrm{CF}_{4}$ & - & - & 22 & - & 35 & 15 & 28 \\
\hline $\mathrm{He} / \mathrm{HFC}$ & - & 12 & 43 & 11 & 26 & - & 8 \\
\hline
\end{tabular}


for the deterioration of hydrophobicity of the film coated at $100^{\circ} \mathrm{C}$.

\section{Conclusion}

In this study, super hydrophobic a-C:F film was successfully deposited on PC substrate by DBD using fluorocarbon gas at atmospheric pressure and room temperature. The highest contact angle of water on the film deposited with $\mathrm{C}_{2} \mathrm{~F}_{6}$ was $155^{\circ}$. From the XPS results, there was $40 \%$ of $\mathrm{C}_{-} \mathrm{CF}_{3}$ bonding at the surface of the super hydrophobic film. The rms roughness value of the film was relatively high and the topography of it showed fine and sharp end. The contact angle and deposition rate were decreased with increasing substrate temperature. The contact angle was high when the surface microstructure of the film was fine and sharp at similar roughness and chemical composition of the surface.

In the case of using $\mathrm{CF}_{4}$ and $\mathrm{HFC}$ gas as a fluorine source, the contact angle of the films was below $120^{\circ}$. The $\mathrm{C}_{-} \mathrm{CF}_{3}$ bonding was not observed on the surface coated with $\mathrm{CF}_{4}$ and HFC. The surface of the films had relatively low roughness value and smooth hillock.

\section{References}

1. R. Blossey, Nat. Mater., 2 (2003) 301.

2. J. T. McCarthy, D. Oner, Langmuir, 16 (2000) 7777.

3. "Physical Chemistry of Surface", A. W. Adamson Eds., John Wiley \& Sons, New York, (1997).

4. R. D. Hazlett, J. Colloid Interface Sci., 137 (1990) 527.

5. Y. Inoue, Y. Yoshimura, Y. Ikeda, A. Kohno, Colloids Surf. B 19 (2000) 257.

6. Y. Chen, Z. Zhao, J. Dai, Y. Liu, Appl. Surf. Sci., 254 (2007) 464.

7. X. M. Li, D. Reinhoudt, M. C. Calama, Chem. Soc. Rev., 36 (2007) 1350.

8. E. Hosono, S. Fujihara, I. Honma, H. Zhou, J. Am. Chem. Soc., 127 (2005) 13458.

9. L. Zhu, Y. Xiu, J. Xu, P. A. Tamirisa, D. W. Hess, C.-P. Wong, Langmuir, 21 (2005) 11208.

10. M. Sun, C. Luo, L. Xu, H. Ji, Q. Quyang, D. Yu, Y. Chen, Langmuir, 21 (2005) 8978.

11. "Fundamentals of Plasma Chemistry and Technology", H. V. Boenig, Tehchnomic Publishing Co. Inc. Lancaster · Basel (1988) 25. 